\title{
Analysis of Current and Desirable Status of Iran's Basic Health Insurance
}

\author{
Roohollah Gholikhani ${ }^{1}$, Farbod EbadiFard Azar ${ }^{2}$, Mohammad Javad Kabir ${ }^{3}$, Mohammad Mehdi \\ Tadayon $^{4 *}$
}

1. Department of public law, Faculty of law (campus), Tehran University, Tehran, Iran

2. Department of Health Services, School of Public Health, Iran University of Medical Science, Tehran, Iran

3. Department of Family and Community Medicine, School of Medicine Golestan University of Medical Sciences, Gorgan, Iran.

4. National Center for Health insurance Research. (NCHIR). Iran. Health Insurance Organization (IHIO)

\section{Article Type:}

Original Article

\section{Article History:}

Received: 19 Jun 2018

Revised: 02 Sep 2018

Accepted: 20 Sep 2018

*Correspondence:

Mohammad Mehdi

Tadayon, National

Center for Health

insurance Research.

(NCHIR). Iran.

Health Insurance

Organization (IHIO)

E-mail:

Tadayon.m.m@gmail.com

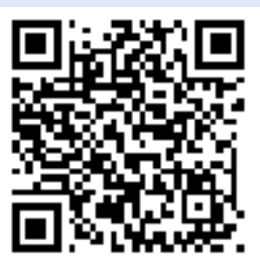

\begin{abstract}
Background and objectives: With regard to unclear government approach in the insurance sector, multiplicity of rules, high share of households, improper population coverage and lack of cost-effective interventions, this study aimed to analyze the current status of basic health insurance in Iran and its distance from the desirable status according to upstream documents. In addition, we attempted to propose a strategy in this regard.
\end{abstract}

Methods: This qualitative research was performed in 2017 in four stages of analysis of the current status of upstream documents and laws, round-table discussions of policymakers, and presenting political options. In total, 20 subjects were selected by targeted sampling method with maximum diversity and based on the saturation rule. Data were collected by document analysis and interviews with authorities. Moreover, data were analyzed applying content analysis and the deductive approach.

Results: The results were classified into five areas of population coverage, financial resources management, and financial protection of insured individuals, strategic purchasing, policy-making, and structure. There was a significant distance between the desirable status based on upstream documents and laws and the current status. Recommendations: eliminating conflicts of interest in decision-making areas, complying with the public interest in making health decisions, observing the principles of the evaluation of regulatory effects, and assessing the economic and social effects of health decisions.

Conclusion: Despite the successful global experiences, the recommendations of the World Health Organization, and the existence of several optimal structures, proper models must be considered by the health system of the country through observing the relevant mechanisms and necessities.

Keywords: Basic Health Insurance; Upstream Documents; Current Status; Desirable Status

Copyright $($ 2018, Jorjani Biomedicine Journal has published this work as an open access article under the terms of the Creative Commons Attribution License (http://creativecommons.org/licenses/by-nc/4.0/) which permits noncommercial uses of the work while it is properly cited. 


\section{Introduction}

Aging, the advancement of medical technologies, and increased community expectations have increased costs. Out-ofpocket payments are common in many countries, which have reduced the ability of people to use services. In 2010, about 150 million people dealt with catastrophic expenditures, and 100 million individuals fell into poverty. Financial security is one of the challenges of the health system in the low and middle-income countries in line with achieving universal health coverage. These countries have inefficient prepaid, tax and social health insurance systems. Despite the high per capita health in Iran, the major part of health expenditures is still paid by the society members (low efficiency of financial resources in the health system of the country). Studies on the fairness of financial contribution index have indicated the low participation of people in resource supply and lack of access to distributive justice. There are still many ups and downs in the path toward achieving the complete coverage of the population, high-quality services, and financial security. Spending costs does not necessarily lead to better health outcomes, and good policy and resource management will be able to produce effective health care (planning of health financing policy is deeply political).

\section{Materials and Methods}

This qualitative study was carried out in four stages of analysis of the status of basic health insurance, analysis of upstream laws and regulations, roundtable stakeholder discussions and presenting policy options. Data collection methods were: (a) document analysis and (b) interview with authorities (the comprehensive analysis of the status quo with primary and secondary research methods). The primary data were collected through informal interviews and round-table discussions. Round-table discussions are an unofficial regulation of the discussion session. Another factor affecting the adjustment and performance of individuals is self-control [6], which can be the opposite of impulsivity in vulnerable women as a multifaceted structure.

Other primary data collection methods would be used in case of lack of achieving sufficient data from the round-table discussions. The main sources of the secondary data were scientific articles and the data published by the ministries of health and welfare (Grey sources were also used). Report on the status quo was applied by accumulating the secondary data, grey literature, and the primary data as the basic data for extraction of political recommendations. In the next stage, all documents and laws related to health insurance were evaluated during 19752017. The research team aimed to collect upstream documents in a targeted manner and evaluate them by library research. In addition, the data were collected from websites of the ministry of health homes, work and social welfare and property, health insurance organization, and social supply organization.

A total of 20 individuals were selected by targeted sampling with maximum diversity to attend the round-table discussions of policymakers. Inclusion criteria were work experience, organizational position, level of education and predominance on policymaking in the area of insurance. The research objectives and method of implementation were explained to the participants before the interviews, and informed consent was obtained. After that, interviews were initiated and continued until data saturation. Analysis of the content of the documents and laws, as 
well as round-table discussions and interviews were carried out using content analysis and deductive approaches. In the latter, the researcher guided the study process using the existing views. At first, the primary classification framework was prepared based on the existing models, and various classifications and models of evaluation of financial supply of the health system or review of the resources and coding were carried out accordingly.

Credibility, transferability and conformability approaches were exploited to confirm the accuracy and strength of the data. The processes of providing a manuscript of discussions and interviews, using the complementary opinions of colleagues, revising the content by the participants, and assessing the data by other researchers were carried out to establish the transferability ability. Researchers increased conformability by allocating sufficient time to the data collection process, reviewing the data multiple times, and attaining the opinions of experts.

\section{Results}

Given the use of the deductive approach, the researchers classified some definitions and qualitatively assessed the content of documents and discussions to find exemplary definitions and generalizations.

- Population coverage of basic health insurance

- Desirable status

- Compulsory and universal basic health insurance

- Current status

While the population coverage of basic health insurance is provided for $97 \%$ of the community, the continuity of free insurance coverage for the covered community is debatable, and there is no reliable and effective mechanism to force individuals to cover basic insurance.

\section{Corrective Measures}

Creating a centralized database and removing overlaps with the possibility of online interaction with other systems (national organization for civil registration and the ministry of health).

Financial resources management of the health system

\section{Desirable Status}

Correcting the structure of funds, rationalizing the tariffs, using the internal resources of funds- sustainable financingquantitative and qualitative development of health insurance- reforming the health system structure- guiding resources for eliminating the subsidies of high-income families to a comprehensive social security system to create social solidarity- paying and targeting subsidies of the health sector- calculating the financial burden of approvals and providing it in the budget laws of the country- managing the resources by the insurance system for optimal management of resources sustainable financial resources with legitimate clarification of incomes, costs, and activities.

\section{Current Status}

Managing $20 \%$ of the health system's financial resources by the insurance system, over $50 \%$ out-of-pocket payments, and $30 \%$ direct payments by the Ministry of Health and supplementary insurance - dispersal of financial resources management, the impossibility of aggregating resource management by the insurance system with the distribution of funds, non-compliance of supplementary health insurance with the rules of the Supreme Council of Insurance, lack of playing a role in policy-making and 
monitoring (e.g., design of guidelines) by the basic insurance, accreditation of hospitals, \% share of government participation from the public sources of basic premiums (paying a higher share for people with higher incomes and conflicts with justice). There is a higher possibility of dealing with lower income deciles with catastrophic expenditures by pushing the major part of public resources toward income deciles with a higher payment ability. Given the fact that the insurance share of more than $90 \%$ of insured individuals is paid by the government, there is resource constraint in terms of accumulation of deferred claims (lack of trusted administrative mechanism for attracting the share of insurers), entry and exit of package services without health technology assessment studies, and lack of scientific relationship between the package and basic health premium. The government's decisions, such as the revision of relative value without funding, are a void commitment to credit.

\section{Corrective Measures}

Aggregating all public health resources under the basic health insurance system for the optimal management of financial resources - defining a list of services based on scientific criteria - prioritizing and apportioning health services - providing integrated health care-based targeted packages - defining a scientific relationship between the service package and insurance premium - determining insurance premium based on cost and not income.

\section{Documents:}

\begin{tabular}{|l|l|}
\hline Column & Title \\
\hline $\mathbf{1}$ & Constitution \\
\hline $\mathbf{2}$ & The Law on the Structure of the Comprehensive Welfare System \\
\hline $\mathbf{3}$ & Universal Insurance Act \\
\hline $\mathbf{4}$ & Five-Year Development Plan Law \\
\hline $\mathbf{5}$ & Law on adding articles to regulation law 2 \\
\hline $\mathbf{6}$ & General Health and Population Policies - 2025 vision plan \\
\hline
\end{tabular}

\section{Characteristics of interviewees}

\begin{tabular}{|l|c|c|}
\hline Column & $\begin{array}{c}\text { Occupation and position-experts- heads of offices- vice- } \\
\text { chancellors and general managers }\end{array}$ & 4 \\
\hline $\mathbf{1}$ & Social security expert & 2 \\
\hline $\mathbf{2}$ & Health insurance expert & 5 \\
\hline $\mathbf{3}$ & Health policy-making experts & 3 \\
\hline $\mathbf{4}$ & Health experts & 2 \\
\hline $\mathbf{5}$ & Experts in health economics and health rights \\
\hline Total & 20 & \\
\hline
\end{tabular}

\section{Financial Protection of Insured Persons Desirable Status}

Promoting a fair financial participation index for the public, people's share of health expenditure up to $30 \%$, and the proportion of vulnerable households in extreme poverty caused by health expenditures must be reduced to less than $1 \%$ and zero. Paying and creating targeted health subsidies - immediate and unconditional treatment of driving accidents victims in all governmental and nongovernmental healthcare institutions - 
modifying the list of basic insurance services, determining the package of comprehensive health services at the level of basic and supplementary insurance by the Ministry of Health and purchasing them by the insurance system, and effective supervision of accurate implementation of packages by the custodian through eliminating unnecessary measures and costs from the cycle of disease diagnosis to treatment- payment system based on performance quality, increased efficiency, creating fair income and paying special attention to health promotion and prevention activities in less-privileged areas, developing the required clinical guidelines, preventing inductive supply and permitting prescriptions solely based on the leveling system and clinical guidelines for financial protection of insured persons.

\section{Current Status}

According to the World Bank report, seven percent of households with basic health insurance and $11 \%$ of families without basic health insurance coverage in Iran suffer from catastrophic expenditures. In addition, there is a high share of out-of-pocket payments, especially in private hospitals and areas such as outpatient sector, drugs, paraclinical and dental costs. Due to the lack of a credible need assessment system, the lack of an appropriate prioritization and rationing system to provide health services, the lack of updating of the list of services of basic health insurance, the disproportionate expansion of modern medical technologies and excessive spread of specialized and subspecialized services, the basic healthcare needs are not completely covered.

Due to the lack of a modified system to establish targeted subsidies, the health subsidies are still being spent in public sector hospitals, which are mainly located in metropolitan areas. On the other hand, excessive reliance of health insurance funds on state resources (changing the nature of funds from insurance-based to supportive) has caused problems in employing insurance mechanisms, such as risk aggregation and distribution in basic health insurance system. Retrospective payment systems, especially the merit pay system, cause the inductive supply phenomenon and impose unnecessary costs on patients.

Executive Order of Article 17 of the Universal Compulsory Insurance Act on the requirement of concluding contracts by institutes that provide services in the private and non-government sectors with basic health insurance does not have a performance guarantee. In addition, there is no clear and modified mechanism to control inductive supply and benefit from complementary, surplus, and supplementary health insurances by rural and nomadic groups and those with non-government jobs. Given the lack of structural integration of different insurance organizations, there is inadequate coverage of disability and retired basic insurances for approximately one-third of the productive population of the country (the lack of longterm financial protections).

\section{Corrective Measures}

Annual review of the list of basic health insurance services based on the results of health technology assessment studies, prioritization and tariff quotas, development of targeted packages for special groups or diseases, development of solutions for directing out-of-pocket payments to prepaid plans, aggregation of all financial resources in basic health insurance and functional 
integration (and structural, if possible), establishment of a multi-layered social security system with the approach of maximum accumulation of state resources in the social assistance layer and provision of free premium and health insurance franchise for those subjected to the services of this layer, establishment of the leveling system, referral and compilation of clinical guidelines, and postponing of cooperation continuity and any payments to health care providers in accordance with the leveling and referral system, the provision and purchase of health services based on integrated healthcare, the requirement of all institutions providing healthcare services to conclude a partnership agreement with the basic health insurance, and creation of the opportunity for the rural and nomadic groups and those with nongovernment jobs to benefit from supplementary and complementary health insurance.

\section{Strategic Purchasing of Health Services Desirable Status}

Revising relative value and determining health service tariffs for all healthcare providers by observing the principle of equilibrium of resources and expenditures, and strategic purchasing of services establishing a stylesheet for mass purchasing of health services and goods in the Supreme Council, reviewing the list of committed services annually on the basis of scientific criteria with priority of the leveling and referral system, compiling a clinical guide entering new services into the list of basic health insurance subject to define a clinical guideline for these services and designing a quality-based payment mechanism.

\section{Current Status}

- High difference between tariffs in the government and private sectors and necessity of purchasing health services from the private sector based on the government tariff in the basic health insurance according to the merit pay system (necessity of paying the costs in the basic health insurance)

- $\quad$ Lack of approval of the stylesheet for mass purchasing of health services and products and targeted service packages with the exception of packages for special patients

- $\quad$ Lack of existence of a modified list of basic health insurance services based on the principles and scientific criteria such as prioritization of services, variable franchises, and payment systems based on performance and quality

\section{Corrective Measures}

Establishment of a united health insurance institution with legal, structural, administrative, and financial independencepurchase of services based on quantitative and qualitative indicators of the centers proportional to the financial ability of the insured persons with the possibility of paying different tariffs for the same services in different geographic areas and for various service providing qualities - performancebased payments, allocation of the responsibility of health technology assessment to the health insurance system, review of the list of basic health insurance services based on the prioritization and rationing organization of healthcare services and the leveling system for providing clinical practice services and guides and postponing the payment of basic health insurance organizations and contract pattern redesign for purchase of services from service providers based on strategic purchasing requirements.

\section{Policy-making and Structure Desirable Status}

Separating the custodian's duties, financing and providing services in the field of health, reforming the health system structure, and 
focusing on all affairs related to health insurances in the health insurance organization.

\section{Current Status}

The multiplicity of theoretical paradigms of policymakers - the dispersion of basic social insurance structures, the lack of coherent strategy and procedure in the current structure of funds - aggregation of policy-making, providing financial services in the Ministry of Health and social security organization - the lack of defining clear policies for the performance of the health insurance system, lack of approval of the bill of Health Insurance by the Supreme Council, distribution of risk accumulation and distribution funds, the lack of ability to optimally manage resources with an insurance mechanism due to the dispersion of the distribution of health resources in the basic

\section{Discussion}

Despite the compulsory nature of insurance, the entire population is not covered before and after the health promotion plan (lack of a centralized database to eliminate overlaps and lack of performing Means tests to remove people who do not need the insurance). South Korea achieved universal coverage by allocating subsidies to premiums and accepting the principle of family affiliation. In Germany, membership in the Disease Fund is compulsory for all workers whose gross income is below the threshold. In Chile, the coverage of the population was extended with the emergence of voluntary mutual assistance organizations and the allocation of subsidies to basic health charities, and later with the role of the government with legislation for compulsory insurance. Using a targeted list insurance organization and the Ministry of Health.

\section{Corrective Measures}

Managing financial resources of the health system by insurance, creating an integrated structure with a centralized policy-making, such as national social insurance organization of Iran or ministry of health and social welfare, approving the bill of the health insurance by the Supreme Council, composing suitable members, the abstraction of medical education from the Ministry of Health and its annexation to the Ministry Science and providing services of the government, private and cooperative sectors, and forming the "ministry of health and social security" (Note 3, Article 11 of the Structure Law, the Government's duty to integrate the two Ministries of Welfare and Health by the end of the Third Development Plan).

based on proxy methods and conducting a Means test to measure income levels of insured persons are also common in Japan, where citizens must register annually in one of the general health insurance programs (performance bond, paying an amount equal to a two-year premium as a fine).

Health insurance funds management through insurance - dealing with low reporting of the incomes of high-income households - taxing and obtaining more money from drug advertising in Korea - different types of taxes, such as income taxes, VAT, and smoking, alcohol, and fuel tax in the UK. Establishing a united social security system for all individuals in the long-term in Chile and Indonesia- an open treasury of central assignment, the responsibility of reorganizing the system for collecting and distributing 
health-related social security contributions in Germany. Increasing prepaid contributions increasing government subsidies rationalizing and expanding the existing service packages - regulating services to deepen service packages and increasing the number of hospitalization services - In South Korea, financial protection guidelines include forcing private sector providers to stay in the national health insurance, increasing package of services, reducing the franchise rate for special diseases, setting a maximum for outof-pocket payments based on income level every six months, and defining a cost-sharing maximum as the income percentage of households.

Insufficient comprehensiveness of articles of law for strategic purchasing- the inadequacy of appropriate policies for coordination between insurer companies and ministry of health - and lack of health technology evaluation (development of a strategic purchasing system in Thailand, Brazil, and South Korea).

Solution: applying a volume control method or maximum budget- process of determining the repayment rate to determine the profit margin of the providers- a fixed budget for drugs to motivate physicians to prescribe generic drugs and introducing a payment system based on diagnosis-related groups, lack of exit of all service providers from the national health insurance and quality purchase plans. Inefficiencies occur in sharing health costs due to conflicts caused by interference in the roles of policy makers and service provision. In Thailand, the integrated model of public health ministry has been changed as the role of purchaser due to the formation of the self-governing national health security office (NHSO) (the South Korea model of policy-making by the ministry of health and welfare at the national level- managing the national health insurance with two pseudogovernment organizations).

Final recommendation: one of the proper models with relevant mechanisms (successful global market of Bench Market and recommendations of the global health organization and presence of several suitable structures of health system) must be selected and move toward the approach of cost management, structural integration, aggregation of resources and sustainable resource supply for maximum supply of interests of the nation. Elimination of conflicts of interest in decision-making areas, regulatory impact assessment and evaluation of socioeconomic effects of decisions. Despite the in-depth evaluation of the principle of government guarantee in the field of health and social welfare, the formation of fixed obligations with unstable resources has been overlooked.

\section{Acknowledgements}

None

\section{Declarations}

\section{Conflict of interest}

We declare that we have no financial or non-financial conflicts of interest related to the subject matter or materials discussed in the article.

\section{Authors' contributions}

All authors contributed equally to this work.

\section{References}

1. F. T. Healthcare policies over the last 20 years: Reforms and counterreforms.2010;95(1):82-9. 
2. WHO The world health report 2010 Health systems financing: The path to universal coverage. Geneva: WHO, 2010.

3. World Health Statistics 2015.

4. Rezapour A, Ghaderi H, Azar FE, Larijani B, Gohari MR. Effects of health out-ofpocket payment on households in iran; catastrophic and impoverishment: issues. 2013;12:13.

5. Fazaeli AA, Seyedin H, Moghaddam AV, Delavari A, Salimzadeh H, Varmazyar H, et al. Fairness of financial contribution in Iranian health system:... 2015;7(5):260.

6. Hsiao WC. Why is a systemic view of health financing necessary?. 2007;26(4):950-61.

7. Fifth development Program Islamic Consultive Assembly(Majleis) of Iran. 2011.

8. Kwon S. Thirty years of national health insurance in South Korea: Health policy and planning. 2008;24(1):63-71.

9. Frenz P, Delgado I, Kaufman JS, Harper S. Achieving effective universal health coverage with equity: evidence from Chile. 2013;29(6):717-31.

10. Ikegami N, Yoo B-K, Hashimoto H, Matsumoto M, Ogata H, Babazono A, et al. Japanese universal health coverage. 2011;378(9796):1106-15.

11. Universal Health Coverage for Inclusive and Sustainable Development:Country Summary Report for Thailand. 2014 - Brazil.

\section{How to cite:}

Gholikhani R, EbadiFard Azar F, Kabir M.J, Tadayon M.M. Analysis of Current and Desirable Status of Iran's Basic Health Insurance. Jorjani Biomedicine Journal. 2018; 6(4): 53-61. 